\title{
SARS-CoV-2/COVID-19 pandemic produces a new paradigm for international hematopathology meetings
}

\author{
William R. Macon ${ }^{1}$
}

Published online: 17 May 2021

๑ The Author(s), under exclusive licence to Springer-Verlag GmbH Germany, part of Springer Nature 2021

Some of the effects of the SARS-CoV-2/COVID-19 pandemic on the practice of hematopathology have been documented in this journal [1]. Another area this pandemic has impacted has been on conducting scientific meetings, including those international meetings within our field.

The 20th European Association for Haematopathology (EAHP)-Society for Hematopathology (SH) Symposium and Workshop, scheduled for September 11-16, 2020, in Dubrovnik, Croatia, was postponed due to the COVID-19 health risks of holding a large international meeting in person in a relatively small venue. The hope that this meeting could take place in its original face-to-face format in April 2021 was dashed by the continuation of the pandemic, which necessitated its cancellation.

Technological advances now allow for online "virtual" meetings. One of the earliest scientific conferences to be held virtually during the pandemic was hosted by the American Association for Cancer Research (AACR), which replaced its April 24-29, 2020, in-person meeting with a two-part virtual conference [2]. The first part (AACR I) was conducted from April 27 to 28, 2020, and the number of registrants for it (61,000 from 140 countries) was far greater than those typically attending the comparable face-to-face meeting [2]. The ability to reach a truly global audience that includes viewers from resource-limited countries is one benefit of virtual conferences [3].

The recent EAHP-SH Symposium and Workshop held on April 25-29, 2021, was a testament to the successes for virtual meetings as there were 900 participants from 71 countries and six continents [4]. There was a mixture of pre-recorded and live presentations. Platform talks were live and were followed by live question and answer sessions with the speakers. Completed sessions could be viewed "ondemand" for attendees, a particularly useful feature for those in time-zones inconvenient for real-time viewing.

With the availability of vaccines to SARS-CoV-2, the 2021 SH-EAHP Workshop on "Transformation and transdifferentiation in lymphoid malignancies" will be held on November 4-6, 2021, in Philadelphia, PA, USA, in a live setting [5]. It will also allow for a virtual audience. This combination of in-person and on-line viewing offers the advantages of both formats, which may become the paradigm for the future of international hematopathology meetings.

\section{References}

1. Macon WR (2020) COVID-19 and remembering Professor Dennis H. Wright. J Hematopathol 13:77-78

2. Speirs V (2020) Reflections on the upsurge of virtual cancer conferences during the COVID-19 pandemic. Br J Cancer 123:698-699

3. Houston H (2020) Lessons of COVID-19: virtual conferences. J Exp Med 217(9):e20201467

4. EAHP ${ }^{\mathrm{SH}} / \mathrm{VIRTUAL}$ (2021) Become a sponsor. https://www.eahpsh2021.com/sponsor/

5. SH-EAHP (2021) Workshop. https://www.society-for-hematopath ology.org

Publisher's note Springer Nature remains neutral with regard to jurisdictional claims in published maps and institutional affiliations.
William R. Macon

macon.william@mayo.edu

1 Mayo Clinic, Rochester, MN, USA 